\title{
Invasive cystic hypersecretory carcinoma of the breast associated with papillary pattern: a rare and poorly recognised variant of ductal carcinoma of the breast
}

\author{
Parul Gupta ${ }^{1}$, Sonal Dhingra ${ }^{1}$, Osman Musa ${ }^{2}$ and AN Srivastava ${ }^{1}$ \\ 1Department of Pathology, Era's Lucknow Medical College and Hospital, Lucknow 226003, India \\ 2Department of Surgery, Era's Lucknow Medical College and Hospital, Lucknow 226003, India
}

Correspondence to: AN Srivastava. Email: ans4csmmu@gmail.com

\begin{abstract}
Cystic hypersecretory pattern is a rare and poorly recognised variant of invasive ductal carcinoma of the breast. Cystic hypersecretory lesions of the breast have a spectrum of morphological features ranging from clearly benign cystic hypersecretory hyperplasia ( $\mathrm{CH} H$ ), $\mathrm{CHH}$ with atypia, cystic hypersecretory carcinoma $(\mathrm{CHC})$ to invasive $\mathrm{CHC}$. Until now, no case of invasive $\mathrm{CHC}$ has been reported in India, to the best of our knowledge. We report a case of a 57-year-old female with a history of a lump in the inferomedial quadrant of the right breast for three years, gradually increasing in size. A mammography showed a well-defined, lobulated radio-opacity. A modified radical mastectomy was done. Gross examination showed multiple cystic spaces filled with thick gelatinous material and solid areas. On histopathology, cystic hypersecretory variant of invasive ductal breast carcinoma with focal papillary pattern was diagnosed. Cystic hypersecretory ductal carcinoma behaves in a low-grade fashion for many years but has a potential for invasiveness and metastasis, so regular follow-up of such cases is crucial.
\end{abstract}

Keywords: breast, carcinoma, mastectomy

Published: 04/11/2014

Received: 08/08/2014

ecancer 2014, 8:477 DOI: 10.3332/ecancer.2014.477

Copyright: (c) the authors; licensee ecancermedicalscience. This is an Open Access article distributed under the terms of the Creative Commons Attribution License (http://creativecommons.org/licenses/by/3.0), which permits unrestricted use, distribution, and reproduction in any medium, provided the original work is properly cited. 


\section{Introduction}

Cystic hypersecretory carcinoma $(\mathrm{CHC})$ and cystic hypersecretory hyperplasia $(\mathrm{CHH})$ was first described in 1984 [1]. $\mathrm{CHC}$ is an uncommon distinctive variant of ductal breast carcinoma in situ that arises in the background of $\mathrm{CHH}$ and is characterised grossly by the presence of dilated ducts and cysts containing glistening, gelatinous material, and microscopically areas of micropapillary carcinoma in the epithelium lining the cyst [2]. $\mathrm{CHC}$ is thought to behave in an indolent manner but has the potential to give rise to invasive carcinoma [3]. An invasive component has been reported approximately in $20 \%$ of $\mathrm{CHC}$ cases, and it tends to be poorly differentiated ductal carcinoma with solid growth pattern and no secretory activity [2]. Positive reactions for periodic acid schiff (PAS), carcinoembryonic antigen (CEA), alpha-lactalbumin have been observed in the cyst contents, which are consistently negative for thyroglobulin. CHC are usually estrogen receptor (ER) and HER-2/neu positive [4]. There have only been a few cases of invasive $\mathrm{CHC}$ reported in the literature. We describe an additional new case of invasive $\mathrm{CHC}$ in a 57-year-old female, and the relevant literature is reviewed [Table 1].

Table 1. Review of cases of $\mathrm{CHC}$ in the literature.

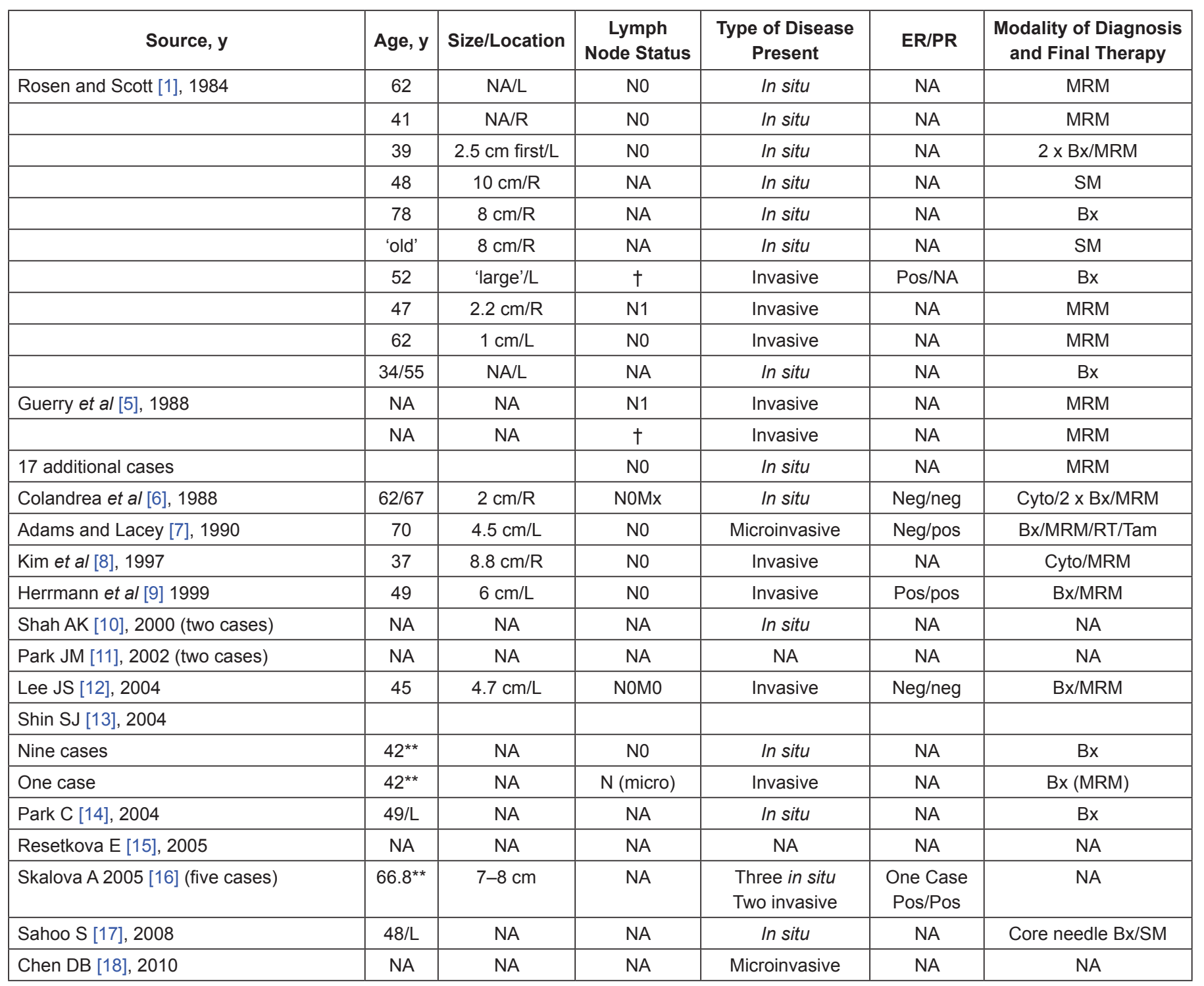


Table 1. Continued.

\begin{tabular}{|l|c|c|c|c|c|c|}
\hline Song SW [19], 2011 & 43 & NA & NA & Invasive & NA & Bx \\
\hline D'Alfonso TM [20], 2014, Mean (ten case) & $62.8^{* *}$ & $0.9 \mathrm{~cm}^{*}$ & NA & Nine in situ & 7 pos/2 pos & NA \\
\hline & & & NA & One microinvasive & Pos/pos & MRM \\
\hline Bi R [21], 2014 (three cases) & $49.3^{* *}$ & NA & NA & $\begin{array}{c}\text { One in situ } \\
\text { Two invasive }\end{array}$ & pos/1 pos & Neg/neg \\
\hline Present case & 57 & $7 \mathrm{~cm}$ & No & invasive & MRMs \\
\hline
\end{tabular}

"ER/PR indicates estrogen receptor/progesterone receptor; NA: not available; L: left breast; R: right breast; pos: positive; neg: negative; MRM: modified radical mastectomy; Bx: biopsy; SM: simple mastectomy; Cyto: cytology; RT: radiation; and Tam: tamoxifen;

$\mathrm{N}$ (micro): lymph node micrometastasis.

"Mean age

†Indicates cases with distal metastatic disease.
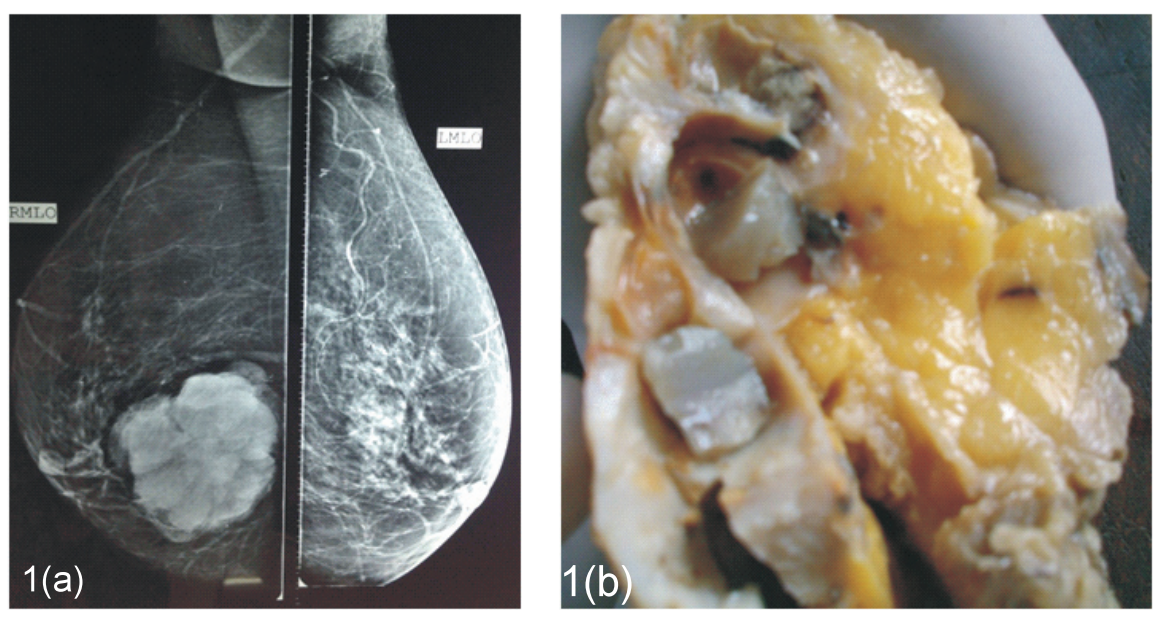

Figure 1. (a). Mammography, mediolateral oblique view showing well defined, lobulated radio-opacity in the right inferomedial quadrant. (b). The cut surface of the mass showing cysts filled with gelatinous secretions.

\section{Case report}

A 57-year-old female presented with a palpable mass in the inferomedial quadrant of the right breast. The lump was gradually progressive in size for the last three years. Physical examination revealed a painless, mobile, ill-defined, hard, $8 \times 7 \mathrm{~cm}$ lump with no retraction of nipple, no nipple discharge, and no axillary lymphadenopathy. The patient had no history of benign breast disease previously or family history of breast cancer. A mammography showed a well-defined, lobulated radio-opacity in the inferomedial quadrant of right breast (Figure 1a).

The patient underwent a modified radical mastectomy. Grossly, the cut surface revealed a $7 \times 7 \mathrm{~cm}$ tumour which showed multiple cystic spaces filled with thick gelatinous material and grey-white solid areas (Figue 1b). Microscopically, the tumour showed varied histological pattern with predominantly multiple variable- sized cystic spaces filled with PAS positive dense eosinophilic material resembling thyroid colloid (Figure 2a). These homogenous secretions were retracted from the surrounding epithelium producing a scalloped margin. The cyst lining epithelium exhibited a variable pattern that in most areas was flat to cuboidal (Figure 2a) and in other areas showed a proliferative change in the form of pseudostratification to knobby epithelial tufts (Figure 2b) to complex branching fronds that extend across duct lumen forming a Roman arch bridging pattern (Figure 2c). Areas of intraductal carcinoma (micropapillary type) (Figure 2d) accompanied by an invasive component comprising of solid pattern of moderately to poorly differentiated ductal carcinoma cells (Figure 2e) was seen. Some areas of tumour tissues also showed papillary pattern with fibrovascular core (Figure 2f). Immunohistochemistry (IHC) shows, the cystic contents were negative for CEA and thyroglobulin. Tumour was ER, PR, HER-2/neu negative. 

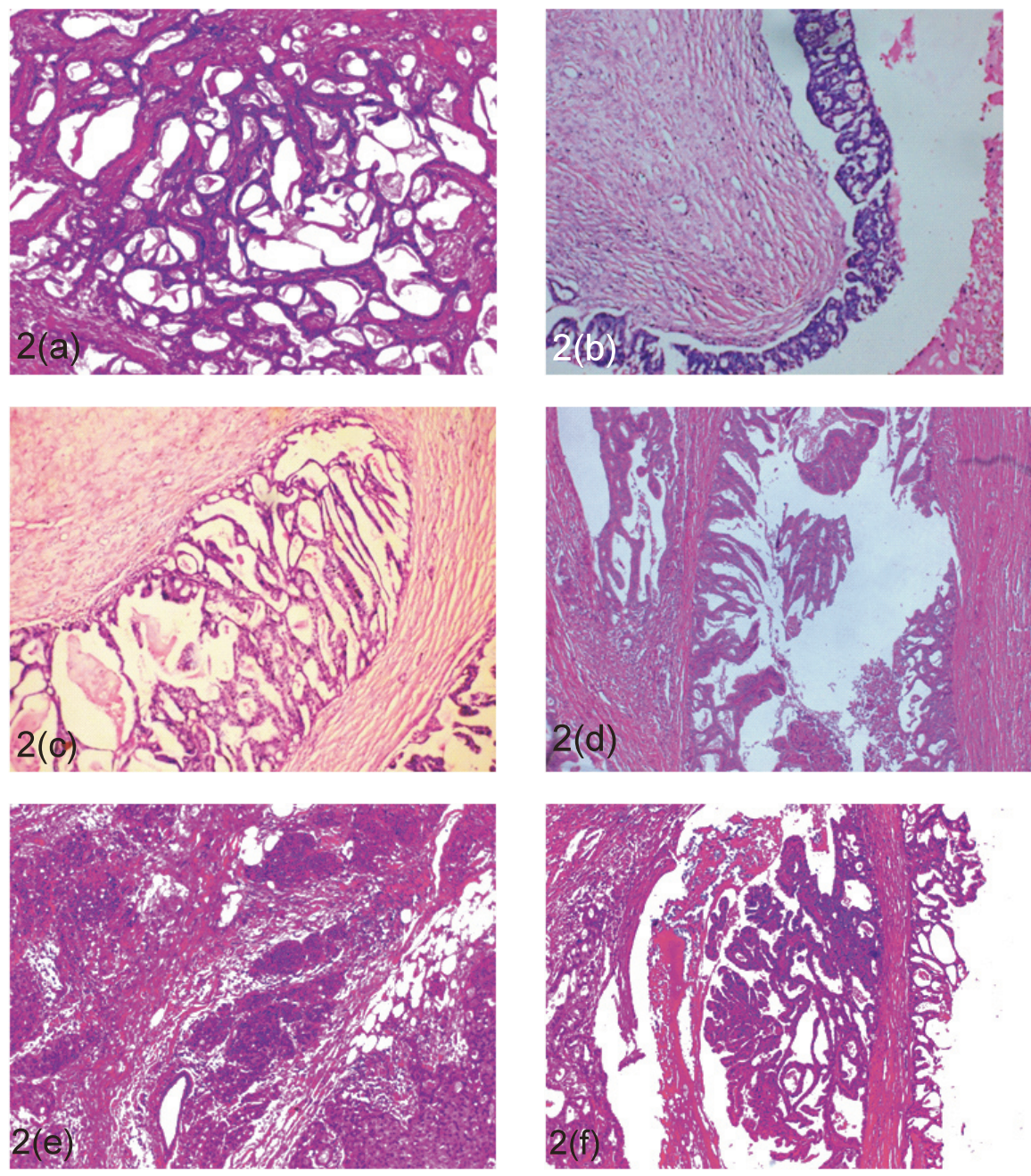

Figure 2. Microscopic findings (H \& E). The lesion is composed of multiple cyst and ducts containing eosinophilic secretions (a; 40x). Some of the cysts are lined by flattened epithelium ( $\mathrm{a} ; 40 \mathrm{x}$ ) while others show epithelial proliferations in form of pseudostratification, knobby tufts (b; 100x), Roman arch (c; 100x), to micro-papillary carcinoma in situ (d; 630X), and invasive pattern in form of solid sheets (e; 100x), and papillary pattern of ductal carcinoma (f; 100x).

A diagnosis of invasive cystic hypersecretory carcinoma was made with focal papillary pattern. None of the axillary lymph nodes were positive for tumour metastasis.

\section{Discussion}

Rosen and Scott defined cystic hypersecretory carcinoma as a subtype of intraductal carcinoma of the breast and described this entity in a series of 10 cases [1]. Since then few authors have put this entity forward generally in the form of case reports and that further invasive $\mathrm{CHC}$ is much rarer (Table 1). Cystic hypersecretory lesions of the breast have a spectrum of morphological features ranging from clearly benign $(\mathrm{CHH})$, a combination of benign and atypical epithelium ( $\mathrm{CHH}$ with atypia), to cases that combine benign, atypical, and frankly malignant epithelium [5]. The characteristic findings of invasive $\mathrm{CHC}$ are formation of dilated ducts filled with eosinophilic colloid-like 
material in their lumens and lined by pseudostratified to micropapillary epithelium along with foci of invasion. Extravasation of cyst material into the stroma does not indicate invasion [1, 5, 11]. Invasion is heralded by solid nests of malignant cells and is usually poorly differentiated with no secretory characteristic. Among the reported cases of cystic hypersecretory breast lesion, most cases are of in situ $\mathrm{CHC}$, with only a few cases of invasive $\mathrm{CHC}$ [Table 1]. So this makes our case extremely rare in the scenario that it is invasive $\mathrm{CHC}$ and also harbours foci of $\mathrm{CHH}$ and $\mathrm{CHC}$ in situ within the lesion and shows an additional morphology of papillary pattern. If no cytological atypia is present and the epithelium is flat or cuboidal, the lesion is characterised as $\mathrm{CHH}$. Foci of the similar picture is seen in our case along with invasive areas and in accordance with long history of gradually progressing breast lump; it appears that the $\mathrm{CHH}$ has progressed to $\mathrm{CHC}$ in situ to invasive $\mathrm{CHC}$ showing the spectrum of evolution of this tumour within the same lesion.

The differential diagnosis of invasive $\mathrm{CHC}$ includes juvenile secretory carcinoma, mucinous carcinoma, malignant mucocele-like tumour, and metastatic thyroid carcinoma. Juvenile secretory carcinoma contains vacuolated cytoplasm and more bubbly secretions which are not typical features of $\mathrm{CHC}$ [22]. Mucinous carcinoma and malignant mucocele-like tumour also show cystically dilated ducts. However secretions of these lesions are rather pale and basophilic and do not show linear cracking artefacts, and the mucinous content are formed from extravasation of mucin within the stroma. Metastatic follicular thyroid cancer may mimic $\mathrm{CHC}$, so a histological differentiation requires IHC stain for thyroglobulin $[12,13,15]$. CHC usually behaves in a non-aggressive manner but few reported invasive $\mathrm{CHC}$ cases, including our case, emphasise the need for follow-up and genetic studies for future risk assessment.

\section{Conclusion}

$\mathrm{CHC}$ in situ of the breast is a rare distinctive variant of ductal carcinoma that behaves in a low-grade fashion for many years but, nevertheless, has a potential for invasive growth and development of distant metastasis. Under-diagnosis of $\mathrm{CHC}$ as a benign lesion that is $\mathrm{CHH}$ is a recognised phenomenon and should be avoided by extensive sampling of the lesion and looking for invasion. It is a persistent condition with the potential to evolve into carcinoma. Longer follow-up and study of additional cases will be necessary to determine if this lesion has distinctive clinical characteristics.

\section{References}

1. Rosen PP and Scott M (1984) Cystic hypersecretory duct carcinoma of the breast Am J Surg Pathol 8(1) 31-41 DOI: 10.1097/00000478-198401000-00003 PMID: $\underline{6320685}$

2. Erdinç Kamer et al (2008) Invasive cystic hypersecretory ductal carcinoma of the breast Meme Sağlığı Dergisi Cilt 4 Sayı 2

3. Skálová A et al (2005) Cystic hypersecretory carcinoma: rare and potentially aggressive variant of intraductal carcinoma of the breast. [Report of five cases] CeskaGynekol 70(1) 73-8

4. Paul Peter Rosen 2009 Rosen's breast pathology chapter cystic hypersecretory carcinoma and cystic hypersecretory hyperplasia 3rd edn 581-589

5. Guerry P, Erlandson RA and Rosen PP (1988) Cystic hypersecretory hyperplasia and cystic hypersecretory duct carcinoma of the breast Cancer 61(8) 1611-1620 PMID: 2832048

6. Colandrea JM et al (1988) Cystic hypersecretory duct carcinoma of the breast Arch Pathol Lab Med 112(5) 560-3 PMID: $\underline{2833875}$

7. Adams GD and Lacey S (1990) Cystic hypersecretory breast carcinoma: an unusual breast cancer Nebr Med J 75(5) 104-108 PMID: 2362619

8. Kim MK, Ghee-Young K and Gyung-Yub G (1997) Fine needle aspiration cytology of cystic hypersecretory carcinoma of the breast Acta Cytol 41(3) 892-896 DOI: 10.1159/000332724 PMID: 9167722 
9. Herrmann ME, McClatchey KD and Siziopikou KP (1999) Invasive cystic hypersecretory ductal carcinoma of breast: a case report and review of the literature Arch Pathol Lab Med 123(11) 1108-10 PMID: 10539918

10. Shah AK et al (2000) Cystic hypersecretory duct carcinoma of the breast Breast J 6(4) 269-272 DOI: 10.1046/j.1524-4741$.2000 .98036 . x$

11. Park JM and Seo MR (2002) Cystic hypersecretory duct carcinoma of the breast: report of two cases Clin Radiol 57(4) 312-5 DOI: $\underline{10.1053 / \mathrm{crad} .2001 .0825}$ PMID: 12014880

12. Lee JS and Lee YJ (2004) Invasive cystic hypersecretory carcinoma of the breast: a case report J Korean Med Sci 19(1) 149-51 DOI: 10.3346/jkms.2004.19.1.149 PMID: 14966360 PMCID: 2822254

13. Shin SJ and Rosen PP (2004) Carcinoma arising from preexisting pregnancy-like and cystic hypersecretory hyperplasia lesions of the breast: a clinicopathologic study of 9 patients Am J Surg Pathol 28(6) 789-93 DOI: 10.1097/01.pas.0000126060.20455.27 PMID: 15166671

14. Park $\mathrm{C}$ et al (2004) Sonographic findings in a patient with cystic hypersecretory duct carcinoma of the breast $\mathrm{J}$ Clin Ultrasound 32(1) 29-32 DOI: $\underline{10.1002 / j c u .10223}$ PMID: $\underline{14705175}$

15. Resetkova E et al (2005) Pathologic quiz case: a large, ill-defined cystic breast mass. Invasive cystic hypersecretory duct carcinoma Arch Pathol Lab Med 129(3) e79-80 PMID: 15737055

16. Skalova A et al (2005) Cystic hypersecretory carcinoma: rare and poorly recognized variant of intraductal carcinoma of the breast. Report of five cases Histopathology 46(1) 43-9 DOI: 10.1111/j.1365-2559.2005.02055.x PMID: 15656885

17. Sahoo $S$ et al (2008) Cystic hypersecretory carcinoma of the breast with paget disease of the nipple: a diagnostic challenge Int J Surg Pathol 16(2) 208-12 DOI: 10.1177/1066896907306843 PMID: $\underline{18417683}$

18. Chen DB and Kan $X$ (2010) Cystic hypersecretory carcinoma with microinvasive carcinoma and cystic hypersecretory hyperplasia of breast: report of a case Zhonghua Bing Li Xue Za Zhi 39(1) 54-5 Chinese PMID: 20388402

19. Song SW, Whang IY and Chang ED (2011) Cystic hypersecretory ductal carcinoma of the breast: a rare cause of cystic breast mass Jpn J Radiol 29(9) 660-2 DOI: 10.1007/s11604-011-0601-y PMID: 21956373

20. D'Alfonso TM et al (2014) Cystic hypersecretory (in situ) carcinoma of the breast: a clinicopathologic and immunohistochemical characterization of 10 cases with clinical follow-up Am J Surg Pathol 38(1) 45-53 DOI: 10.1097/PAS.0b013e31829fc47b

21. Bi R et al (2014) Clinicopathologic features of cystic hypersecretory lesion of the breast Zhonghua Bing Li Xue Za Zhi 43(1) 25-9 Chinese PMID: $\underline{24713245}$

22. Hamele-Bena D, Cranor ML and Rosen PP (1996) Mammary mucocele-like lesions, benign and malignant Am J Surg Pathol 20(9) 1081-1085 DOI: 10.1097/00000478-199609000-00005 PMID: $\underline{8764744}$ 